\title{
Christian Lagarde, Des écritures bilingues. Sociolinguistique et littérature
}

\section{Maria Margherita Mattioda}

\section{(2) OpenEdition}

1 Journals

\section{Edizione digitale}

URL: https://journals.openedition.org/studifrancesi/41437

DOI: 10.4000/studifrancesi.41437

ISSN: 2421-5856

\section{Editore}

Rosenberg \& Sellier

\section{Edizione cartacea}

Data di pubblicazione: 1 juillet 2004

Paginazione: $240-241$

ISSN: 0039-2944

\section{Notizia bibliografica digitale}

Maria Margherita Mattioda, «Christian Lagarde, Des écritures bilingues. Sociolinguistique et littérature», Studi Francesi [Online], 142 (XLVIII | I) | 2004, online dal 30 novembre 2015, consultato il 09 septembre 2021. URL: http://journals.openedition.org/studifrancesi/41437 ; DOI: https://doi.org/10.4000/ studifrancesi.41437

Questo documento è stato generato automaticamente il 9 septembre 2021.

\section{(c)}

Studi Francesi è distribuita con Licenza Creative Commons Attribuzione - Non commerciale - Non opere derivate 4.0 Internazionale. 


\title{
Christian Lagarde, Des écritures bilingues. Sociolinguistique et littérature
}

\author{
Maria Margherita Mattioda
}

\section{NOTIZIA}

CHRISTIAN LAGARDE, Des écritures bilingues. Sociolinguistique et littérature, Collection Sociolinguistique, Paris, L'Harmattan, 2001, pp. 257, ISBN 2-7475-0316-X.

1 Il volume di Christian Lagarde riporta all'attenzione del pubblico la "parole variable», affrontando il tema del bilinguismo secondo una prospettiva linguistico-letteraria che si inserisce, da un lato, nel dibattito teorico della sociolinguistica relativo allo statuto e agli usi dei vari idiomi, dall'altro nelle teorie della rappresentazione romanzesca in quanto luogo privilegiato di espressione della varietà del linguaggio. L'indagine focalizza l'attenzione sulle scritture bilingui, intese come modalità di raffigurazione di un'esperienza fondante - la condivisione di codici linguistici diversi e dalla loro interazione- , attraverso l'analisi di una produzione narrativa costituita di dieci opere scritte in sette lingue diverse. A partire dall'esplorazione del campo in oggetto, l'autore tenta una definizione della nozione mediante il raccordo fra diglossia e scrittura. Se quest'ultima è mimesi o trasposizione della realtà, con tutte le sue strutture, e se la prima è situazione di contatto e di definizione identitaria, la scrittura bilingue costituisce un terreno fertile per l'incontro dialettico fra due lingue. Essa è, dunque, uno spazio dinamico in cui le linee di movimento sono vincolate ad una «relation de domination» che può produrre immagini stereotipate del dominé - dall'alto verso il basso se assurgono a giustificazione ideologica dello status quo oppure dal basso verso l'alto se servono la causa della contestazione -, ma anche rappresentazioni complesse del Sé rifratto - il dominant tenta di captare la propria immagine all'interno del gruppo e il dominé, permeabile agli stereotipi predominanti, rimanda il punto di vista dell'altro. «Ecrire bilingue» diviene, quindi, l'espressione di una duplice necessità - il bisogno di 
«dire le monde» $\mathrm{e}$, al contempo di «se dire au monde» - e il punto di convergenza fra lingua, scrittura e potere, da cui si dipartono percorsi enunciativi originali, imbricati sul rapporto dominant/dominé e légitimation/éradication.

In questo quadro complesso che tenta di definire l'oscillazione della parola e l'inafferrabilità del locutore in una situazione socio-culturale plurima, Ch. LAGARDE identifica alcune tipologie di scrittura bilingue - il tipo «couleur locale», il tipo «donner à connaître», il tipo «lutte des langues» - , e ne fornisce una descrizione attenta e puntuale al fine di offrire uno strumento esegetico ed estetico per la decodificazione di testi narrativi generati in situazione di diglossia. Il primo tipo corrisponde alla scrittura narrativa tradizionale nella quale il narratore onnisciente si esprime nella lingua veicolare, mentre l'altra affiora solo nel discorso diretto esplicitato da marche transcodiche. In questo caso, l'elemento esotico interviene in maniera ambigua: l'interesse per la specificità culturale è fittizia e le strategie di scrittura tentano di celare il conflitto linguistico. La seconda tipologia risulta simile alla precedente, pur distaccandosene profondamente a livello dell'ideologia linguistica dell'autore che si rivela partigiano sincero della lingua dominata, considerandola parte della propria identità. Questo tipo di scrittura appare in maniera estremamente diversificata e può essere testimoniata da inserimenti vernacolari oppure da occorrenze e procedimenti narratologici che sono indizio di una volontà di tradurre una coesistenza pacifica delle lingue in contatto.

3 Il tipo «lutte des langues» mette in scena l'aspetto conflittuale delle relazioni interlinguistiche e pertanto risulta dialogico o polifonico. Il tessuto narrativo è, generalmente, improntato al discorso diretto per permettere il confronto fra i codici e il contesto sociale, politico, economico e culturale di una collettività. La rappresentazione della visione conflittuale può, inoltre, manifestarsi con un'imperfetta fusione interlinguistica che mette in evidenza due tratti caratteristici della diglossia: da un lato la prossimità/promiscuità delle due lingue, dall'altro il carattere incerto di questo contatto che è all'origine di profonde contraddizioni negli individui. Da un punto di vista linguistico e letterario, quest'ultima tipologia costituisce, forse, la scrittura più innovativa in quanto l'autore deve necessariamente confrontarsi tra un bilinguismo egualitario e un funzionalismo rivelatore di situazioni di diglossia.

4 La seconda parte del volume si presenta sotto forma di études de cas intese a esemplificare le modalità di funzionamento della diglossia, a partire da testi selezionati e organizzati tematicamente che spaziano dall'Europa all'America, con particolare attenzione per le aree francofone e ispanofone. In apertura e in chiusura di questa sezione segnaliamo gli studi relativi alla lingua francese: il capitolo Langue et vision $d u$ monde (Occitanie- France), che propone la visione dello stesso territorio sulla base di scelte linguistiche differenti («Points de vue sur la Lande: pays et identité chez François Mauriac et Bernat Manciet») e il capitolo Habiter une autre langue (Argentine- France) relativo a Hector Bianciotti, scrittore emblematico di espressione francese, ma di origine sudamericana, eletto all'Académie Française («De la pampa au quai Conti: Hector Bianciotti, transfuge linguistique et culturel»). 